\section{- Luciana Murari²}

Pontifícia Universidade Católica do Rio Grande do Sul

Porto Alegre - Rio Grande do Sul - Brasil

\title{
Resumo
}

Esse artigo busca descrever e analisar a trajetória da Bandeira Anhanguera, expedição realizada em 1937 sob a liderança de Hermano Ribeiro da Silva. O grupo, que partiu de São Paulo, ambicionava explorar a região localizada à margem esquerda do rio das Mortes, no Brasil central, tida como uma das extensões mais desconhecidas do território nacional. Visando produzir conhecimento científico e realizar contato com os indígenas xavantes, até então refratários ao contato com os brancos, o empreendimento buscou mobilizar a sociedade paulista, e para tal fez intenso uso dos meios de comunicação de massa, sobretudo o rádio e a imprensa escrita. A trajetória do grupo é, assim, reconstituída sumariamente, a partir da cobertura jornalística e dos relatos memorialísticos de três de seus participantes.

\section{Palavras-chave}

Relatos de viagem - Memorialismo - Jornalismo - Expedições exploratórias Brasil central.

\footnotetext{
Todas as obras e documentos utilizados na pesquisa e na elaboração do artigo são citados nas notas e na bibliografia. Artigo não publicado em plataforma de preprint.

2 Doutora pelo Programa de Pós-graduação em História Social do Departamento de História da Faculdade de Filosofia, Letras e Ciências Humanas da Universidade de São Paulo. Professora adjunta da Escola de Humanidades e do Programa de Pós-graduação em História da Pontifícia Universidade Católica do Rio Grande do Sul (PUCRS). Bolsista de produtividade em pesquisa do Conselho Nacional de Desenvolvimento Científico e Tecnológico (CNPq).
} 
Contact

Av. Ipiranga, 6681 Prédio $8-4 .^{\circ}$ andar - sala 403 90619-900 - Porto Alegre - Rio Grande do Sul - Brazil luciana.murari@pucrs.br

\section{- Luciana Murari}

Pontifícia Universidade Católica do Rio Grande do Sul

Porto Alegre - Rio Grande do Sul - Brazil

\begin{abstract}
This article seeks to describe and analyze the "Bandeira Anhanguera", an expedition carried out in 1937 under the leadership of Hermano Ribeiro da Silva. The group, which travelled from São Paulo, sought to explore the region located on the left bank of rio das Mortes, a river in central Brazil, considered one of the most unknown extensions of the national territory. Aiming to produce scientific knowledge and make contact with the Xavante natives, who until then were refractory to contact with other peoples, the enterprise sought to mobilize São Paulo, and for this purpose made intense use of the mass media, especially the radio and the written press. The group's trajectory is thus summarily reconstituted, based on the journalistic coverage and the memorialistic reports of three of its participants.
\end{abstract}

\title{
Keywords
}

Travel reports - Memorial narratives - Journalism - Exploratory expeditions Central Brazil. 
Entre julho e dezembro do ano de 1937, um grupo de quarenta homens, liderados pelo sertanista Hermano Ribeiro da Silva, empreendeu uma viagem exploratória até a Serra do Roncador, localizada na mesopotâmia dos rios Araguaia, das Mortes, Xingu e Kuluene, com o objetivo de realizar pesquisas científicas e estabelecer contato com os índios xavantes, que até aquele momento não haviam sido ainda, na linguagem da época, "pacificados". O chefe da expedição havia realizado, até aquele momento, quatro viagens à região central do país, das quais haviam derivado duas publicações de considerável repercussão no meio editorial brasileiro: Nos sertões do Araguaia: narrativas da expedição ás glebas barbaras do Brasil central (1935) e Garimpos de Mato Grosso: viagens ao sul do Estado e ao lendario Rio das Garças (1936). Com isso, ele havia angariado notável prestígio nos meios cultos da capital paulista, o que o qualificava a assumir a liderança do empreendimento, não apenas como aventureiro dotado da necessária experiência, mas também como cronista habilitado a narrá-la.

Apesar dessa expectativa de publicização dos eventos da expedição, seu organizador não sobreviveu para contá-los: acometido por malária, faleceu em uma fazenda às margens do rio das Mortes em 24 de novembro de 1937, quando o grupo iniciava seu retorno a São Paulo. Sua morte o confirmava como expressão paradigmática da atualização do mito bandeirante, como descendente das elites tradicionais paulistas e explorador intrépido em nome do progresso do país, em uma encarnação midiática apropriada ao entusiasmo nacionalista característico do período imediatamente anterior à Segunda Guerra Mundial. Batizada de "Bandeira Anhanguera", a caravana então realizada foi produto de um massivo trabalho de propaganda, responsável por converter o projeto de seu líder em uma grande mobilização coletiva.

Nesse artigo, busca-se elaborar uma narrativa sintética dos eventos vividos pela Bandeira, como uma trajetória radical de sobrevivência em ambientes desconhecidos e escassamente povoados, no contexto de um projeto nacionalista de apropriação objetiva e simbólica de territórios situados fora do alcance da institucionalidade estatal. Compreende-se esses eventos como parte de uma aventura, experiência que Georg Simmel definiu como algo que "extrapola o contexto da vida, [...] uma parte da nossa existência à qual - pela 
frente e por trás se ligam imediatamente outras, mas que, ao mesmo tempo, em seu sentido profundo, corre por fora de qualquer continuidade desta vida.". Apesar de contingente e de extraterritorial em relação à existência corriqueira, a aventura equivale a uma demanda emblemática e a um significado profundo que está além das motivações puramente racionais de seu sujeito, como "corpo estranho em nossa existência, que, no entanto, é de alguma forma ligado ao centro." (SIMMEL, 1998, p. 171). Para compreender tais motivações, faz-se necessário descrever o terreno ideológico do empreendimento.

Para elaborar tal narrativa, utilizam-se os textos memorialísticos legados por três participantes da expedição. O primeiro deles, Na Serra do Roncador - a vanguarda da Bandeira Anhanguera, foi publicado no ano seguinte à realização da expedição. Foi, portanto, escrito ainda "no calor da hora" por um de seus subchefes, Francisco Brasileiro, amigo íntimo de Hermano e personagem significativo de seus relatos de viagem publicados em 1935 e 1936 (BRASILEIRO, 1938). "Chicão", como era conhecido em função de seu porte avantajado, foi responsável por abrir caminho para o avanço da Bandeira, e já havia explorado o território próximo às tribos xavantes quando, em 1932, formou um grupo para esse fim com dois alemães, um tcheco e quatro sertanejos (SILVA, 1935, p. 29). Trata-se do mais longo e detalhado relato disponível. Embora eivado de evocações literárias e de diálogos em discurso direto, esse texto valoriza o registro documental do cotidiano do grupo, e não evita abordar passagens vexaminosas e inglórias, tampouco se furtando a narrar as soluções truculentas adotadas pelo próprio narrador para lidar com as situações de conflito geradas no convívio do grupo ${ }^{3}$.

O segundo relato, Entre índios e revoluções, de Darcy Bandeira de Melo, foi publicado no início dos anos 1980 como parte do volume de memórias do autor, outro dos subchefes da expedição ${ }^{4}$. A narrativa dos eventos da Bandeira expressa seus sentimentos e percepções, mas também confere considerável atenção ao aspecto documental, coligindo um conjunto valoroso de mensagens, telegramas e memorandos da Bandeira. O autor, que já possuía experiência de viagens ao Brasil central, trabalhava como vendedor de peças para automóveis desde 1933, e não tinha planos de abandonar a perspectiva

\footnotetext{
3 A partir de 1943, Brasileiro atuou como subchefe da Expedição Roncador-Xingu, junto a seu grupo paulista, novamente no trabalho de vanguarda (VILLAS BÔAS, Orlando; VILLAS BÔAS, Cláudio, 2012, p. 29).

4 De um total de 275 páginas de texto, 55 tratam da Bandeira Anhanguera, compreendendo os capítulos IV a XI da segunda parte da obra.
} 
de um "futuro bastante promissor" no ramo em que atuava até receber o convite de Hermano. De fato, depois da viagem ele reassume o posto de gerente comercial em São Paulo. Também está longe de ser um relato asséptico, registrando inclusive os ciúmes despertados pela relação íntima de Hermano com o outro subchefe: “[...] Hermano aceitava tudo que o 'Chico' fazia, mesmo sem o conhecimento prévio dos outros chefes, ainda que resultasse em erro!" (MELLO, 1980, p. 205, 213).

O terceiro livro, Bandeira Anhangüera: viagem à Serra do Roncador, de Antonio Senatore, consiste em um diário de viagem que permaneceu inédito até $2001^{5}$. Filho de pais italianos, nascido em São Paulo e educado na Itália, havia tomado parte, entre 1926 e 1928, do "raid fluvial", expedição esportiva e científica que partiu de São Paulo a bordo de uma canoa e chegou a Mato Grosso, depois de passar por Argentina, Uruguai e Paraguai. Senatore viveu dois anos no Pantanal mato-grossense, "commerciando com pelles e procurando apanhar aspectos sensacionaes para um fita cinematographica" (NO RUMO..., 12 maio 1937). Na Bandeira, atuou como fotógrafo e cozinheiro, mostrando-se um de seus elementos mais atuantes. Encontram-se nesse diário os registros mais crus a respeito do cotidiano do grupo, sobretudo no que diz respeito à revelação de desavenças e inimizades. Trata-se de um documento informativo desprovido de maiores elaborações intelectuais, bastante pessoal em seu registro do vivido e, particularmente, na expressão de seus descontentamentos. O diário foi escrito com base em anotações feitas ao longo da jornada, mas há sinais de que o texto foi revisto ou ampliado posteriormente, como se verifica pelo uso de sentenças em que o narrador manifesta reflexões gerais acerca de sua experiência de viagem ou antecipa eventos (SENATORE, 2001).

Movido por um espírito de engajamento e conclamação da opinião pública, o jornal $O$ Estado de S. Paulo, patrocinador de primeira hora da iniciativa, proporciona uma cobertura regular dos fatos e algo próximo a um "discurso oficial" dos seus promotores. As notícias da viagem, difundidas em primeira mão pelo Estadão a partir dos radiogramas enviados in loco pelos expedicionários, eram a partir de então repercutidas por outros jornais brasileiros. Além desse material jornalístico, é possível também contar com o relatório elaborado pelo engenheiro Arnaldo Otávio Nébias, publicado pela Revista

\footnotetext{
5 Esse diário de viagem foi escrito em italiano, e se encontrava depositado, juntamente com álbuns de fotografia e recortes de jornal, no Museu Histórico da cidade de Cáceres, no Oeste do estado do Mato Grosso, tendo sido publicado em edição bilíngue (SENATORE, 2001).
} 
Brasileira de Geografia em seu volume de abril de 1940. A despeito de seu caráter técnico, o texto também apresenta algumas informações de interesse para a descrição da experiência vivida pelo grupo. A partir dessas informações, é possível acompanhar a trajetória da Bandeira a partir de dentro (NÉBIAS, 1940, p. 155-72).

\section{A maravilhosa viagem dos sonhos}

O marco inicial da história da Bandeira Anhanguera pode ser identificado com a palestra "Nos sertões do Brasil", pronunciada por Hermano Ribeiro da Silva no Instituto Histórico e Geográfico de São Paulo, em 18 de março de 1937, o que já ilustra o reconhecimento público conquistado pelo autor por meio de seus livros. A publicação integral do texto, no dia 26 daquele mês, indica que àquela altura possivelmente já tivessem sido iniciadas as tratativas para o patrocínio d'O Estado de S. Paulo a sua próxima empreitada, que o sertanista definia como sua "maravilhosa viagem dos sonhos". Essa consistiria em uma incursão em "zonas totalmente indevassadas, quer pelas prodigiosas bandeiras de Piratininga de antanho, quer pelos mais rusticos caboclos pioneiros das entradas, quer pelas missões catequistas, ou quer pelas caravanas de finalidades scientificas" (SILVA, 1937). De fato, a região a ser explorada, localizada à margem esquerda do rio das Mortes, em Mato Grosso, não havia sido ainda descrita geográfica e cientificamente, ao mesmo tempo que um véu de mistificações cobria a imagem do povo xavante, que lá habitava, o que se devia efetivamente a sua resistência à inserção na sociedade sertaneja e ao contato com os "agentes civilizadores", principalmente os religiosos que buscavam sua catequização.

A fala de Hermano, que retoma ideias já defendidas em seus livros, ecoa a influência de Euclides da Cunha, literalmente citado em alguns trechos da conferência, sobretudo ao acusar a desídia da elite republicana em relação à promoção de conhecimento, à ocupação produtiva e à presença do estado nos territórios interiores do país. Fiel à lógica euclidiana do contraste dramático, o palestrante afirmava que mapas e estudos produzidos fora do Brasil possuíam condição de excelência, "em chocante contraposição com a infinidade de modernos mappas nacionaes, que apparecem eivados de flagrantes erros." Para a região que pretendia explorar, o melhor mapa disponível havia sido produzido pela missão Rondon e apresentava diversos pontos de interrogação, evidenciando a existência de zonas que, virtualmente, jamais haviam sido percorridas pelo homem branco. Missão de "descoberta", a Bandeira visava à apropriação efetiva daquele território, como parte de uma 
"radical transformação da mentalidade da nossa gente, afim de converter o seu affecto á terra em um amor mais pratico e mais fecundo." (SILVA, 1937).

Assim, à ênfase que o autor d'Os sertões conferia a questões de ordem estratégica e geopolítica, o palestrante sobrepõe interesses imediatamente econômicos, fazendo apelo ao retorno material associado à exploração dos recursos naturais disponíveis no Brasil central. O diagnóstico euclidiano, somado a elevadas doses de produtivismo, resultava em um projeto de "elevar o grau da cultura indigena e de quebrar o nosso civismo gongorico, aproveitando as fascinantes possibilidades economicas que offerece a região." (SILVA, 1937). Esse argumento era inseparável de um propósito científico que contribuiria para alavancar a autenticação social do empreendimento, com sua proposta de promover o mapeamento, a descrição geográfica e a prospecção de riquezas no território, simultaneamente abrindo caminho para a pacificação dos xavantes.

Ao mesmo tempo, o sertanista assumia uma retórica defensiva mediante a qual definia seus propósitos como uma resposta à ameaça ao interesse nacional identificada com o expansionismo de companhias estrangeiras nos territórios da Amazônia e do Brasil central, o que era particularmente

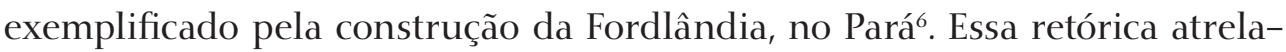
va seu projeto pessoal ao interesse público, o que a revestia de significado missionário e evidentemente patriótico, colorido com as tintas da denúncia e do alarme. A experiência do palestrante em suas viagens ao Centro-oeste do país referendava seu diagnóstico, pois seus livros registravam seu encontro com exploradores de origens diversas, "criaturas de instrucção já adiantada, verdadeiros technicos, escondidos sob a humildade de simplorios aventureiros andejos." De fato, em suas narrativas de viagem os principais personagens que convergem com o narrador são estrangeiros, que visitam a região com os mais variados objetivos, da exploração de oportunidades econômicas à mera aventura, passando pela prospecção de riquezas minerais, a pesquisa em geografia e ciências biológicas e a cristianização dos nativos, o que descrevia "o entranhado amor com que poderosos representantes das nações de alem-mar assistem ao espectaculo do nosso desleixo e do nosso perdularismo." (SILVA, 1937).

O resultado, em sua avaliação, era a abundância do acervo de museus estrangeiros em itens extraídos do território nacional, "traduzindo extraor-

\footnotetext{
6 Empreendimento criado por Henry Ford com vistas a promover o plantio de seringueiras para a provisão industrial de látex, cuja história se estende de 1927 a 1945. Ver Grandin (2010).
} 
dinario desfalque nas collecções que acaso quizermos realisar algum dia". Esse raciocínio é, sem dúvida, pouco plausível, embora uma virtual ameaça de esgotamento das riquezas nacionais nas mãos de potências estrangeiras fizesse sentido dentro da retórica de autolegitimação adotada pelo sertanista. O contraponto a esse interesse internacional pelo território brasileiro, que assume relevo à luz de seu testemunho, é que, continuava Hermano, "paradoxalmente nunca me avistei nos sertões com patricios esclarecidos entregues ás uteis pesquisas, nem tão pouco obtive noticias de quaesquer recentes passagens de conterraneos illustrados que se dedicassem a taes empenhos". Definia-se, assim, o "vulto de inferioridade que esses acontecimentos representam no nosso indice cultural", diagnóstico sombrio que clamava pelo heroísmo de homens excepcionais como ele próprio. O recurso à analogia histórica, que conduziu ao batismo da expedição como Bandeira Anhanguera, convergia com um processo cultural em andamento desde as últimas décadas do século XIX, por meio do qual a elite paulista criava e difundia manifestações culturais, literárias e historiográficas voltadas para a promoção do culto das expedições de prospecção mineral e apresamento de índios como instrumentos de interiorização da colonização e conquista territorial, transmitindo uma imagem de arrojo e liderança no contexto nacional que chegou à geração modernista ${ }^{7}$.

Dentro do espírito de conquista próprio ao discurso de culto aos bandeirantes, o ineditismo referendava por si só o valor da façanha, apresentada publicamente pela primeira vez nessa ocasião. A proposta evoluiu para assinatura de contratos de patrocínio junto ao jornal $O$ Estado de $S$. Paulo e à Sociedade Rádio Bandeirante ${ }^{8}$, que conjuntamente adotaram a iniciativa. Em contrapartida, os expedicionários comprometiam-se a fornecer notícias da Bandeira em primeira mão para os dois veículos, através de mensagens telegráficas e transmissões radiofônicas. Em 9 de maio de 1937, é feito o primeiro anúncio público do acordo nas páginas do Jornal, que registra a divulgação dos propósitos da bandeira pelo microfone da Rádio:

Nos itens do programma da caravana surgem objectivos de reaes e ressaltantes proveitos para o engrandecimento cultural do paiz, taes como: investigações e colheita de materiaes

\footnotetext{
7 Para uma análise circunstanciada desse fenômeno, em torno da produção literária regionalista e da atuação do Instituto Histórico e Geográfico de São Paulo, ver Ferreira (2002).

8 A Rádio Bandeirante foi criada por José Nicolini em 1936, mas sua fundação deu-se em 6 de maio de 1937, o que permite definir o patrocínio e a cobertura da Bandeira Anhanguera como uma de suas primeiras iniciativas (ADAMI, 2014, p. 101).
} 
de ethnographia indigena, da zoologia, da botanica e da geologia, comprehendendo a geographia local e as pesquisas mineralogicas (todo o material scientifico reunido deverá permanecer nos institutos de S. Paulo, a criterio dos patrocinadores da missão); e a filmagem cinematographica instructiva das innumeras occorrencias das rusticas jornadas. Como se percebe, além do altamente valioso desbravamento inicial de immensas regiões brasileiras, subsistem no projecto obrigações de variadas pesquisas, cujo vulto, no que toca ao engrandecimento das sciencias, não precisa de commentarios. (NO RUMO..., 1937).

Já nessa ocasião, é anunciada a abertura de uma subscrição pública com vistas ao financiamento da Bandeira, e definido seu custo em 100 contos de reis, para um grupo de quarenta homens e por um período de oito meses. $\mathrm{O}$ relato de Francisco Brasileiro documenta a expectativa inicial do líder da expedição de que a quantia seria amealhada unicamente por meio da contribuição espontânea da população paulista, que reconheceria os nobres objetivos da expedição e a identificaria, por uma espécie de instinto regionalista, com a nobre missão histórica do bandeirantismo (BRASILEIRO, 1938, p. 11). Os patrocinadores da iniciativa inseriram regularmente em sua pauta espaços para promover a Bandeira. Na Rádio, criou-se o programa noturno de divulgação "Hora Bandeirante", no qual seus promotores, participantes e incentivadores difundiam os propósitos do empreendimento e conclamavam o público a oferece-lhe suporte. No jornal, passam a ser divulgados textos informativos e de propaganda. Outros jornais dão espaço para a divulgação do empreendimento, como o Correio Paulistano, que entrevistou Hermano em reportagem altamente positiva para a imagem de seu projeto (UMA BELLA..., 1937).

Até a partida da expedição, esses textos buscarão estimular a contribuição do público, com base na refutação da ideia de que a Bandeira pudesse ter objetivo de lucro. "A reduzida quantia requerida para o custeio da comitiva destróe desde logo a idéa de um immediato lucro commercial (...)", argumenta a coluna de 14 de maio de 1937 (NO RUMO..., 14 maio 1937). Defende-se, na ocasião, que a única compensação do grupo, de acordo com contrato assinado com os patrocinadores, consistiria nos possíveis lucros do documentário a ser filmado durante a viagem e no resultado de trabalhos de mineração porventura desempenhados.

A reduzida quantia requerida para o custeio da comitiva destróe desde logo a idéa de um immediato lucro commercial, menos elogiavel por parte dos expedicionarios. Elles, em troca do devassamento de enorme [sic] glebas desconhecidas e habitadas por indios completamente selvagens, de uma magnifica colheita de peças ethnographicas e de uma extraordinaria contribuição para diversos ramos da sciencia indígena, material esse que será doado a instituições culturaes de São Paulo (...). (NO RUMO..., 14 maio 1937). 
Como parte desse esforço, os organizadores da expedição fizeram circular o livro de ouro da Bandeira Anhanguera, legalizado pelos patrocinadores e contendo frases de incentivo aos expedicionários redigidas pela Comissão de Honra, composta por personagens de renome no meio intelectual paulista, que referendariam o interesse científico do empreendimento9 ${ }^{9}$ Na segunda quinzena de maio, eles foram convocados a se dirigir ao público, pelo microfone da Rádio Bandeirante, para dar testemunho de sua confiança nos propósitos da Bandeira (15 maio 1937). Também ficou deliberado que caberia a essa Comissão analisar a prestação de contas da expedição (NO RUMO..., 16 jun. 1937).

O referendo da opinião pública avançava, simultaneamente, no sentido da legitimação social e aquisição de prestígio pelos promotores da caravana, o que resultou na obtenção de um financiamento governamental no valor de quarenta mil-réis. O aporte foi concedido por meio de projeto de lei n. ${ }^{0}$ 104, apresentado pelos deputados Paulo Duarte e Pinto Antunes e defendido, em detalhes, na Assembleia Estadual por Miguel Coutinho. O governador José Cardoso de Mello Neto sancionou a iniciativa sob a argumentação de que se tratava de um "ato de paulistismo" e de uma contribuição exígua, comparativamente ao custo de empreendimentos do gênero liderados por estrangeiros. ${ }^{10}$

Busca-se impor, assim, a ideia de que a iniciativa seria uma resposta nacionalista ao interesse e ao poderio financeiro dos exploradores forâneos. No entanto, apesar do apoio da classe política e da campanha dos meios de comunicação, entre o público a desconfiança quanto aos verdadeiros propósitos da Bandeira parece ter prevalecido, e a subscrição pública teve resultados frustrantes: $6 \$ 380$ contos de réis. As maiores contribuições foram oferecidas pela fábrica de Laticínios Vigor, o Banco do Estado de São Paulo, os patrocinadores Rádio Bandeirantes e Estadão, além de donativos de prefeituras, fábricas, lojas e companhias de seguro. Além das contribuições financeiras, a Bandeira recebeu auxílios variados, como passagens e transporte gratuito de bagagem nas companhias ferroviárias paulistas e doações de latas de leite em pó, equipamentos científicos, barracas de lona da campanha de 1932, armas e munições, filtros, remédios, antissépticos e vacinas (REVIVENDO..., 3 jul. 1937).

\footnotetext{
9 A Comissão de Honra da Bandeira era composta por representantes das seguintes instituições: Museu Paulista, Instituto de Pesquisas Tecnológicas, Departamento de Indústria Animal, Clube Zoológico de São Paulo, Instituto de Higiene, Associação Comercial, Instituto Histórico e Geográfico e Universidade de São Paulo. Somavam-se a elas promotores das publicações $O$ Estado de S. Paulo e Enciclopédia Brasileira (NO RUMO..., 13 maio 1937).

${ }^{10}$ Inicialmente, a subvenção proposta era de vinte mil-réis, sendo na ocasião apresentada uma emenda que elevava o valor para sessenta mil-réis (SÃO PAULO, 1937).
} 
Enquanto em termos financeiros a Bandeira não obteve de fato a totalidade dos recursos com que contava, foi maciço o interesse manifestado por voluntários interessados em se incorporar ao grupo, mais de uma centena, não havendo registro de que alguma dessas postulações tenha sido aceita. De fato, antes do início dessa campanha de arrecadação de fundos a composição do núcleo central do grupo já estava definida, a partir dos contatos de Hermano com outros viajantes e do critério da experiência prévia em viagens pelo interior do Brasil, ou seja, do "passado sertanista" do expedicionário. Em alguns casos, a fundamentação da escolha dos participantes parece pouco consistente. Oyama Rondon, por exemplo, segundo reportagem do jornal $O$ Estado de S. Paulo, tinha sido selecionado por possuir "larga pratica da vida roceira e das pescarias no rio Parahyba", enquanto Luiz de Moraes Navarro, era um "devotado pesquisador de vastos trechos do rio Tietê, cujos obstáculos das águas lhe são familiares."

Além dos membros escolhidos por seus conhecimentos sertanistas, em muitos casos representados, na reportagem jornalística, por sua familiaridade com a malária, o jornal apresenta os especialistas que desempenhariam os trabalhos técnico-científicos que, afinal, confeririam legitimidade social à Bandeira, como um empreendimento moderno e afinado com o progressismo daquele tempo, de acordo com o estabelecido no programa difundido pelo Estadão:

Visivelmente surgem aos espiritos os frutos presentes e futuros da iniciativa, sendo certo aproveitarem-se da mesma, pelo menos, observações geographicas de real alcance e ainda observações de um caracter economico geral, no que respeita ás condições de utilidade da terra e do seu aproveitamento para a colonização posterior. A flora e a fauna locaes tambem devem ser abarcados nesses estudos. De tal forma sobrarão revelações de inexcedivel valor, como elementos iniciaes para as vindouras actividades das referidas sciencias indigenas, ainda em flagrantes desfalques nesse particular (NO RUMO..., 13 maio 1937).

O programa científico da expedição era, de fato, bastante genérico, ficando a cargo de um grupo limitado de técnicos e especialistas encarregados de realizar estudos, levantar informações e coletar material para compor as coleções de instituições científicas: Jorge do Rego Freitas, professor de química industrial no ginásio de Campinas, agrimensor e inspetor regional do Instituto Biológico, responsável pela coleta de informações geológicas; Arnaldo Otávio Nébias, engenheiro mecânico e elétrico com experiência no interior do país; Walter Garbi, um dos componentes mais velhos do grupo, que havia realizado várias viagens pelo Museu Paulista, no Norte, Centro-oeste e Nordeste do país, como auxiliar taxidermista e fotógrafo técnico; Fábio Fabiano Alves, botânico do Instituto Biológico de São Paulo; Arion 
Bueno Oliveira, médico da expedição, encarregado de realizar pesquisas no campo da medicina tropical. O levantamento de informações etnográficas ficaria a cargo do próprio Hermano Ribeiro da Silva e de Darcy Bandeira de Mello, que possuíam experiência prévia em viagens sertanistas e já haviam entrado em contato com tribos indígenas cristianizadas, mas que de fato não dispunham de formação específica na área (NO RUMO..., 13 maio 1937).

A estratégia utilizada pela organização da expedição consistia em buscar articulações com as instituições de pesquisa de São Paulo para definir objetivos considerados mais relevantes do ponto de vista científico. Na impossibilidade de arregimentar acadêmicos realmente dispostos a uma aventura tão insalubre e perigosa, previa-se que o levantamento de dados seria feito em acordo com as sugestões colhidas junto a membros de entidades como o Instituto Histórico e Geográfico de São Paulo, a seção paulista da Associação Brasileira de Geografia, o Instituto de Higiene, o Clube dos Zoólogos, as Faculdades de Medicina e de Filosofia e Ciências Humanas da Universidade de São Paulo, o Observatório Astronômico, o Instituto Butantan, o Museu Paulista, também estando previsto o contato com cientistas da Missão Rockefeller. Definiam-se, assim, os objetivos de interesse acadêmico da expedição: levantar dados acerca da tuberculose entre as populações indígenas afastadas do contato com os brancos - o que pressupunha um contato bem mais próximo com os xavantes do que aquilo que poderia ser considerado razoável naquele momento; investigar os alimentos, bebidas e medicamentos utilizados pelos indígenas, e descrever suas técnicas de preparação; além de metas imprecisas, como a de realizar "estudos sobre a acustica do homem primitivo", e das investigações habituais no campo da medicina tropical, como a identificação de moléstias de incidência regional, obtenção de informações relativas à malária, o estudo dos vetores entomológicos e da febre amarela. Nesta, como em outras áreas, nomes de destaque do meio científico paulista foram mobilizados, tais como os de Pirajá da Silva, Pierre Monbeig, Frederico Carlos Hoehne e Alípio Leme de Oliveira. Esse último, diretor do Observatório Astronômico do Estado, recebeu naquela instituição o engenheiro Nébias, que lá estagiou por cerca de um mês para adquirir os conhecimentos necessários à coleta de dados climatológicos e aferição de coordenadas geográficas (REVIVENDO..., 4 jul. 1937).

Durante a fase de divulgação da iniciativa e de busca de arregimentação de contribuições financeiras, as ideias a respeito da contribuição científica da Bandeira têm evidente propósito propagandístico, apresentando proposições pouco realistas como a efetivação de pesquisas acerca da formação geológica da região, com a coleta de materiais relativos a jazidas minerais de valor eco- 
nômico, sobretudo de carvão e petróleo, além de pedras e metais preciosos. Na linguagem da mistificação bandeirantista então em voga, ali talvez "perdurem no seus depositos alluvionaes virgens, adormecidas dentro dos caldeirões e das reentrancias das lajes dos rios, riquezas mineraes identicas ás que, carreadas daqui pelos antigos bandeirantes na época do dominio portuguez, foram remettidas para as côrtes de Lisboa." Outras ideias, como a de realização de trabalhos arqueológicos, "pesquisando cavernas, grutas, fosseis, annotando possiveis inscripções" e de "collecta e classificação de craneos, esqueletos ou fosseis por ventura encontrados em cemiterios velhos e abandonados" podem igualmente ser arroladas nesse grupo de propostas desprovidas de fundamentação técnica, humana e material (NO RUMO..., 14 maio 1937).

Além dos componentes que não assumiram funções específicas, selecionados por suas supostas habilidades sertanistas, e do grupo científico, a Bandeira incorporou também técnicos responsáveis pela comunicação com o público e pelo registro dos seus feitos. O envio de notícias regulares a São Paulo, previsto no contrato assinado por Hermano com os patrocinadores da Bandeira, ficou a cargo do radiotelegrafista alemão Walter Glaser, que operava um aparelho transmissor e receptor cedido pela Secretaria de Segurança Pública do Estado. Acompanhavam o grupo também o cinematografista Carlos Feltes e o fotógrafo Antonio Senatore, anteriormente citado com um dos memorialistas da expedição. A difusão do cotidiano do grupo e a documentação de suas façanhas demonstram o componente midiático precocemente incorporado pelo projeto como um meio de obtenção dos recursos para uma incursão sertaneja bem mais consistente e ambiciosa que as "expedições de indigentes" que Hermano Ribeiro da Silva e Francisco Brasileiro haviam até então realizado (BRASILEIRO, 1938, p. 3). Ainda que os objetivos financeiros inicialmente planteados não tenham sido inteiramente atingidos, a mobilização da opinião pública contribuiu para legitimar a concessão de auxílio governamental ao empreendimento.

\section{Pronta qualquer sacrifício, unida para tudo}

Em 25 de julho de 1937, um domingo, a maior parte dos integrantes paulistas da Bandeira deixou São Paulo, rumo a Anápolis. A despedida da Bandeira, irradiada pela Rádio Bandeirante, pode ser definida como um daqueles momentos "que reclamam a continuidade com um passado histórico adequado, organizando cerimónias, paradas e reuniões de massas e construindo novos espaços rituais", nos dizeres de Paul Connerton (1993, p. 62). Após missa solene pelo sucesso na expedição, na igreja de São Francisco, 
os expedicionários, familiares e o público geral se reuniram no Pátio do Colégio, ao som da banda da Força Pública estadual. Lá houve a cerimônia de oferecimento das bandeiras de São Paulo e do Brasil, sendo a flâmula da Bandeira Anhanguera entregue ao grupo por uma criança. Posteriormente, deu-se uma apresentação de canto orfeônico de alunos da Escola Normal Padre Anchieta, dirigida pelo maestro João Julião, entoando o "hino da Bandeira Anhanguera". Seguiram-se os discursos do professor Pereira da Cunha, da mesma escola, que "historiou os feitos dos nossos antepassados e enalteceu o emprehendimento da 'Bandeira Anhanguera'", seguidos pela fala de Agenor Couto de Magalhães, em nome da Comissão de Honra da Bandeira, e pelo agradecimento de Hermano, "que accentuou a sua affirmação de fé" (PARTIDA..., 1937). O grupo seguiu então para a Basílica de São Bento, onde foram depositadas duas coroas de flores no mausoléu de Fernão Dias. Os expedicionários realizaram então uma visita aos estúdios da Rádio Bandeirante, após a qual uma parte deles seguiu para o Cemitério da Consolação, onde prestou homenagem ao Dr. José Augusto de Toledo Filho, participante que faleceu poucos dias antes de seguir como médico da Bandeira. Também foi prestada homenagem a Marina de Toledo Piza, escolhida "madrinha da Bandeira Anhanguera". Hermano Ribeiro da Silva decidiu, entretanto, continuar em São Paulo, em busca de recursos financeiros e logísticos adicionais (BANDEIRA..., 4 nov. 1937).

Enquanto $O$ Estado de $S$. Paulo difundia o discurso oficial dos promotores e apoiadores da expedição, outros órgãos de imprensa acompanhavam a iniciativa, mas faziam dela leituras peculiares. Reportagem do jornal $O$ Globo, por exemplo, registrou a chegada do grupo ao Brasil central, chamando a atenção para as correntes de viajantes que buscavam conhecer a nova capital e registrando o encontro de três caravanas naquele momento. Além da Bandeira Anhanguera, Goiás recebia a Bandeira Piratininga, liderada pelo jornalista Willy Aureli, e uma expedição de caça e recreio procedente de Minas Gerais." "Grande também é o numero de estrangeiros que se encontram entre nós, em excursões turisticas, atraidos pelas immensas possibilidades de riquezas naturaes que apresenta o Brasil central e pelos espetaculos selvagens que o Araguaya proporciona aos civilizados", afirma a matéria,

\footnotetext{
${ }^{11}$ Exemplos de outras excursões ao Brasil central foram a Expedição Morbeck, para prospecção de ouro, em 1936, e a Bandeira Piratininga, de Aureli, que esteve na região em 1937 e retornou no ano seguinte. O encontro da citada expedição de caça com a Bandeira Anhanguera foi narrado em Brasileiro (1938, p. 78).
} 
estampada por uma foto de parte da Bandeira Anhanguera em frente ao Grande Hotel de Goiânia. Nesse contexto, até mesmo o contato com os "ferozes Chavantes" é tratado como uma atração e como um objetivo da "corrente de turistas" que, segundo o texto, dirigia-se aos rios das Mortes e Araguaya. A iniciativa de Hermano é aí inserida no contexto desse movimento amplo de curiosidade pela região que mantinha os hotéis da cidade constantemente cheios. O próprio texto escrito pelo líder da Bandeira Anhanguera para a reportagem d'O Globo concentra-se em distribuir elogios à nova capital, vista como um prodígio de civilização e uma promessa de prosperidade para o sertão, o que se coaduna perfeitamente com o papel eminentemente político assumido por Hermano na ocasião, uma vez que o envolvimento das autoridades abria alternativas de viabilização do projeto em curso (RUMO..., 1937).

Em Anápolis, o grupo visitou o zoólogo Carl Lako, que fazia pesquisas na região sob os auspícios do Instituto Rockefeller, e "que nos transmittiu varias informações de ordem scientifica, tendo sido gentilissimo. (...)", conforme registra telegrama enviado pelo grupo nos primeiros dias de sua estadia em Goiás (A “BANDEIRA..., 1937). Os contatos sociais e a congratulação com as autoridades contribuíram decerto para a expedição, uma vez que o governo de Goiás disponibilizou dois caminhões para transportar o grupo e sua carga de Anápolis e Goiânia até Santa Leopoldina, na margem direita do rio Araguaia, onde a caravana chegou em 5 de agosto. Em batelões, seus membros desceram o rio até as proximidades da vila de Cocalinho, já na margem esquerda do rio, onde foi estabelecido o marco zero da Bandeira, batizado "Porto Anhanguera". A partir daí, caminhariam até a Serra do Roncador, sendo o destino definido como o posto indígena Bakairi, a nordeste de Cuiabá, que desde sua criação, em 1920, havia se tornado um importante ponto de apoio para as expedições de exploração do norte do Mato Grosso (BARROS, 2003, p. 87). O objeto era chegar a uma longa extensão de terras situada à margem esquerda do rio Araguaia, limitada ao norte pelos rios formadores do Xingu e ao sul pelo rio Cristalino, "uma das poucas regiões desconhecidas do mundo", o que dependeria de transpor a Serra do Roncador (NA SERRA..., 17 jul. 1938).

No momento inicial, a expedição contava com quarenta homens e trinta e três animais de carga e sela, e portava cerca de duas toneladas de materiais. O corte considerável no orçamento em relação ao planejamento inicial, que previa a contratação de vinte auxiliares sertanejos para o transporte ao longo do percurso, conduziu os organizadores a decidir que a maior parte dos expedicionários faria o percurso a pé, e o trabalho de montagem e desmontagem da carga seria também realizado por eles próprios (MELLO, 1980, p. 
219). Embora a princípio as medidas de economia não devessem comprometer o transporte de material científico, missão precípua do empreendimento, acabaram por ter graves implicações para a rotina da viagem, sobretudo em sua etapa final, quando o acúmulo de volumes passa a comprometer a viabilidade do retorno do grupo. Montados a cavalo seguiriam apenas os componentes da vanguarda, formada por Francisco Brasileiro, Sílvio Schnoor e pelo guia sertanejo Antonio Severo, sitiante da região, que abriam picadas e certificavam-se do percurso até as aldeias dos xavantes. Esse grupo "furador de mato" (BRASILEIRO, 1938, p. 128) recebeu de Bandeira de Mello o epíteto de "trinca comodista" (MELLO, 1980, p. 233).

Desde o primeiro momento profundamente comprometida com os meios de comunicação de massa, e obrigada por contrato a abastecer a imprensa de notícias de sua jornada, a expedição havia conseguido autorização especial dos Ministérios da Guerra e da Viação para operar uma estação portátil de rádio e telegrafia que, em contato com a radiopatrulha de São Paulo, lhe permitiu realizar transmissões regulares de notícias da Bandeira ao longo da viagem (MELLO, 1980, p. 211). Em sua maioria, as mensagens transmitidas estavam longe de comunicar a realidade cotidiana da expedição, adotando como "chapa final" de suas mensagens a expressão: "Muito mel, muita caça. Todos estão bem." (BRASILEIRO, 1938, p. 153). Ao invés disso, os memorialistas em geral narram um cotidiano de privações materiais, desconforto, esforço físico e conflitos constantes no interior do grupo. Um sinal disso é que, entre os últimos dias de agosto e os primeiros de setembro, antes mesmo do ingresso na margem esquerda do rio das Mortes, onde seriam realizadas as tentativas de contato com os xavantes e a exploração da serra do Roncador, o grupo já se havia reduzido de 40 para 28 homens, dos quais 22 vindos de São Paulo e os demais agregados em Goiás. É compreensível que nem todos os participantes da caravana, que a princípio haviam sido selecionados por sua familiaridade com o ambiente sertanejo ou por seu preparo técnico-científico, encontravam-se em condições de prosseguir em uma marcha que Bandeira de Mello estimou de 25 a 30 quilômetros diários, em temperaturas de 36 a 40 graus Celsius (MELLO, 1980, p. 217-8).

Ao comunicar-se com São Paulo a partir do acampamento às margens do rio das Mortes, em 20 de setembro, Hermano atribuiu as defecções exclusivamente a problemas físicos e, depois de listar nominalmente todos os componentes que permaneciam no grupo, escreveu: “Demais companheiros, motivo exclusivo saúde abalada, grandes cansaços, receberam todos possíveis recursos financeiros, prestígio moral, viagem volta São Paulo. Turma agora fortíssima. Pronta qualquer sacrifício, unida para tudo. Tenho orgulho 
novos bandeirantes [sic]." (BRASILEIRO, 1938, p. 133-4). Na verdade, seis caravanistas retornaram voluntariamente a São Paulo, alegando incapacidade física para resistir às longas caminhadas e aos esforços necessários ao manejo da carga. Três foram dispensados, aparentemente pelo mesmo problema, e outros três foram expulsos em função de seu comportamento errático e belicoso (SENATORE, 2002, p. 38, 40). Em meados de outubro, enquanto procurava por animais extraviados, Francisco Brasileiro encontrou por acaso os padres José Nunes e Hipólito Chovelon, ${ }^{12}$ também interessados em fazer contato com os xavantes. O primeiro, juntamente com seu auxiliar sertanejo, foi então incorporado à Bandeira. No final da expedição, seis participantes da aventura se desentendem com Chicão e retornam a São Paulo separadamente (MELLO, 1980, p. 235-6).

A partir do Porto Anhanguera, o grupo iniciou sua caminhada em direção à Serra do Roncador, dividindo-se em grupos de sete ou oito homens. Completado apenas um mês de viagem, os estoques de alimento do grupo já escasseavam, fazendo que sua sobrevivência dependesse da pesca, da caça e da extração de palmitos, frutas, ovos de tartaruga e mel. No registro de 26 de agosto, o fotógrafo do grupo anota que sua alimentação, tanto pela manhã quanto à noite, baseava-se exclusivamente na jacuba, papa de farinha de mandioca geralmente preparada com rapadura. Os poucos peixes que conseguiram naquele dia trouxeram alegria ao grupo, mas não haviam sido suficientes para afastar a fome. Isso em parte se deveu ao fato de que, buscando, alternativamente, fugir dos xavantes e persegui-los, os esforços de caça da Bandeira haviam sido dramaticamente limitados. A sede torna-se também uma experiência constante.

Uma vez no rio das Mortes, o grupo foi reabastecido, mas os mantimentos mais uma vez eram limitados e, uma semana depois, a ração diária dos caravanistas, que então consistia em um pirão com carne de veado, é reduzida a quantidades muito baixas. Nos dias em que faltava a caça, alimentavam-se de palmito e frutas, às vezes o único alimento disponível, de forma que alguns expedicionários emagrecem tanto que "parecem esqueletos" (SENATORE, 2001, p. 58). Uma das consequências da privação de alimentos era o afinamento da voz, percebido por Chicão depois de doze dias afastado do grupo (BRASILEIRO, 1938, p. 170). O cotidiano da expedição pode ser definido, em grande parte, por uma situação crônica de fome, sede,

\footnotetext{
${ }^{12}$ A respeito da atuação dos sacerdotes salesianos junto aos indígenas, ver Montero (2012).
} 
cansaço, medo dos xavantes e incômodo físico, principalmente em função do sol abrasador, dos mosquitos e da "nevoa secca, que assim se diz da fumaça das queimadas pousada sobre leguas e leguas de caminho sob a forma de extensas nuvens compactas e immoveis rente ao solo, na ausencia absoluta de vento." (NA SERRA..., 17 jul. 1938). Essa situação conduzia, por outro lado, à generalização dos conflitos e das inimizades entre os viajantes. Francisco Brasileiro defende que o radicalismo das circunstâncias conduzia a um desnudamento do caráter individual, como se a aventura conduzisse a uma revelação da verdade de cada um, pois “o convívio constante, as agruras, a soalheira ardente, a fome e os mosquitos famintos fazem ressaltar em toda a sua nudez, despidos de qualquer artifício, os verdadeiros sentimentos e o caráter indisfarçável de cada um." (BRASILEIRO, 1938, p. 38).

Em contrapartida, a presença do grupo também impactava a vida das comunidades por onde ele passava e, ainda que as narrativas disponíveis enfatizem a dinâmica interna da empreitada, apresentam alguns elementos para aferir a marca deixada pela Bandeira ao longo de seu percurso. Segundo Chicão, corria a notícia de que o grupo havia sido enviado pelo governo para construir uma estrada e distribuir terras, o que não deixava de ser uma versão benigna. O governo seria para os sertanejos uma "lenda maravilhosa", cuja autoridade só lhes parecia real à vista dos coletores de impostos, que lhes impunham cobranças monetárias e temíveis exigências documentais. Em um sistema embasado em grande parte no escambo de produtos de subsistência e em que a posse em terras devolutas ainda era mais comum que a propriedade efetiva, esses encargos representavam, diz o cronista, uma considerável perturbação da ordem cotidiana, o que ajuda a explicar a proliferação de boatos como a criação de um novo imposto cobrado sobre a dimensão dos terrenos e não sobre sua produção efetiva e a incorporação da região despovoada entre os rios Araguaia e das Mortes ao estado de Goiás, em detrimento de Mato Grosso. Nessas circunstâncias, o discurso do expedicionário associa a presença do grupo a uma tarefa de esclarecimento e assistência social aos sertanejos, ainda que perfeitamente dentro dos objetivos de promoção do avanço científico em torno dos quais se havia construído o discurso da "Bandeira moderna".

Enquanto isso, o nosso médico Arion suaviza-lhes [aos sertanejos] o sofrimento, tratando os doentes, não deixando, porém, de medir-lhes a capacidade auditiva, de examinar-lhes o sangue e, enfim, de colher os dados de que necessita para os seus estudos sôbre aqueles moradores, que a isso se prestam complacentemente, inclusive alguns carajás que aqui aportaram. De outro lado, o Nébias, nosso engenheiro, atendendo-lhes ao pedido vai organizando rápidos "croquis" das suas fazendas, instruindo-os sôbre a 
maneira de legalizar a situação de cada um perante o Estado. É uma espécie de cura em conjunto do corpo e do espírito (BRASILEIRO, 1938, p. 67).

Como se percebe, o subchefe da Bandeira difunde uma elevada concepção a respeito de seu papel social, acentuando o significado da aventura como uma "missão civilizadora" capaz de levar ao sertão brasileiro alguns dos benefícios da modernidade. Além disso, o grupo trabalharia para sua incorporação ao horizonte intelectual do país como feito de interesse científico e reverberação das viagens exploratórias realizadas pela Missão Rondon, a partir de 1891, e da ação prática de profilaxia e pesquisa dos médicos sanitaristas, a partir de 1910 (LIMA, 1999, p. 72-8, 90-131).

$\mathrm{O}$ contato com indígenas deculturados, sertanejos e missionários religiosos marca também situações de alegria e apaziguamento do grupo, intervalos que, além de ampliarem os limites de seu convívio cotidiano, lhes permitiam desfrutar de uma alimentação mais farta em relação à sobrevivência precária em meio à natureza bruta durante a maior parte do trajeto. Além disso, apesar das condições extremas em que se dá a caminhada, as narrativas de Francisco Brasileiro, Darcy Bandeira de Mello e Antonio Senatore relatam alguns momentos de autêntico gozo da natureza durante a permanência da Bandeira no sertão. Brasileiro assinala o maravilhamento dos excursionistas à vista do "panorama exótico" oferecido pelo Araguaia, com suas areias brancas, suas margens enfeitadas por saranzais, tendo ao redor a floresta densa: "Com exclamações de surpresa e encantamento são saudados os 'manguaris' esguios, as gaivotas arrelientas, os colhereiros rosados e ariscos, os pensativos jaburús e até os bôtos indolentes e inofensivos, em seus mergulhos vadios." Nesse contexto, operava-se uma transformação na psique em direção a um retorno à infância, pois "[o] mais sizudo e retraído torna-se uma criança nos gestos e nas atitudes, despreocupadamente feliz; o misântropo é o mais comunicativo. O ceticismo desaparece; é tudo côr de rosa. Não há mais recalque, os sentimentos transbordam, incontidos." (BRASILEIRO, 1938, p. 41, 42).

O rio Cristalino, particularmente, desperta reações de verdadeiro fascínio, pois, para o fotógrafo da expedição "honra seu nome de batismo, porque as suas águas são límpidas e, mesmo nos pontos mais fundos, consegue-se ver seu leito". E prossegue: "Nas suas margens existem vários laguinhos, que parecem verdadeiras jóias aquáticas; a mão do homem nunca poderia alcançar a perfeição destes cenários; parece que estamos vendo um conto de fadas" (SENATORE, 2001, p. 32). Francisco Brasileiro elabora uma descrição 
lírica do rio, sem abrir mão de observar os aspectos práticos decorrentes dessas características tão encantadoras à vista:

Correndo no seu leito arenoso, apertado pela barranca de areia, infiltra-se por ela para logo mais alargar-se em espraiados ou multiplicar-se em diminutas lagôas. Assim lentamente escorrega, seguindo sem pressa o seu destino. Do seu fundo cresce uma exótica vegetação aquática que lhe empresta um pitoresco encanto, mais parecendo caprichosos ornamentos de genial e inspirado decorador. Nas suas águas cristalinas - que lhe dão o nome que bem merece - vivem em espantosa quantidade, ressaltantes à vista, - qual imenso aquário - magníficos representantes da fauna itiológica. São peixes multicôres, de diversos tamanhos e de feitios diversos, que vemos através das suas águas transparentes. Mas, assim como os vemos, êles também nos vêem, calcúlo, pois de outros outro modo não se explica o desinterêsse com que passam pelos nossos anzóis, demonstrando completo alheamento ao pecado da gula (BRASILEIRO, 1938, p. 96).

Assim como a natureza sertaneja oferece esses momentos de refrigério em meio a jornadas esfalfantes e marcadas por ameaças à sobrevivência e privações fundamentais, o convívio entre o grupo não pode ser resumido aos diversos episódios de confronto entre os viajantes registrados pelos cronistas da expedição. Antonio Senatore classifica dois de seus companheiros - aí incluído Darcy Bandeira de Mello - como "duas pragas que os Chavantes teriam recusado porque fedem demais", mas se refere aos demais como "amigos de desventuras" (SENATORE, 2001, p. 76). Por sua vez, apesar de questionar desde o início as decisões tomadas pelos chefes, e abertamente pretender ocupar um espaço de maior proeminência na expedição, Bandeira de Mello registra os momentos de repouso em que os homens do grupo dedicavam-se a remendar suas roupas e pregar botões, enquanto alguns se voluntariavam para aparar os cabelos dos companheiros. Ele anota também a cantoria noturna, "começada, invariavelmente, pelo Hermano com a sua voz de tenor e coro da Turma", entoando canções sertanejas de Catulo da Paixão Cearense. Acrescenta a isso um tom de humor, ao supor que o canto espantaria os mosquitos e impediria que os "bonzinhos e inofensivos Chavante' se aproximassem do nosso Acampamento, mau-grado a admiração e estima que lhes devotávamos, por serem valentes e audaciosos defensores de suas terras, multissecularmente." (MELLO, 1980, p. 220).

A afirmação demonstra o cuidado com que Bandeira de Mello, e também Francisco Brasileiro, referem-se a seu contato com os xavantes, enquanto a narrativa de Senatore tende a ser mais transparente a respeito dos sentimentos de horror e repulsa inspirados por aqueles que definiu como uma 
"raça cruel e feroz e [que] só com muito sacrifício poderá ser catequizada." (SENATORE, 2001, p. 66). O intento de realizar aquele que seria primeiro contato do homem branco com essa tribo era a meta mais ambiciosa da caravana, e implicava tanto em fotografá-la e filmá-la quanto em coletar material etnográfico destinado a figurar nas coleções dos museus paulistas. A invasão da aldeia foi concretizada mediante o disparo de foguetes que os afugentaram, permitindo que os expedicionários saqueassem de suas casas os materiais que consideraram de interesse científico, deixando, "em troca", bugigangas variadas como espelhos e facas, enquanto eram "observados dedutivamente seus usos e costumes" (BRASILEIRO, 1938, p. 191, 210). Não foram disparados tiros contra a tribo, mas tampouco foram realizados avanços significativos no sentido do contato efetivo. Um entusiasta da iniciativa de Hermano afirmaria posteriormente que "[p]ode, pois, a Bandeira Anhanguera gloriar-se de haver transmittido as primeiras noticias authenticas desses indios." (NA SERRA..., 17 jul. 1938).

Alcançado um dos seus principais objetivos, ao final da expedição a privação de alimentos torna-se ainda mais crítica, especialmente em função do rareamento de animais de caça nas proximidades do território dos xavantes, eles também caçadores. Senatore anota que "se continuarmos assim logo alguém, ou mais de um, irá para o outro mundo", registrando a dificuldade de executar esforços físicos necessários ao retorno e a diarreia que atinge todo o grupo, segundo ele em função da elevada temperatura da água que bebiam. A essa altura, "todos cobiçavam as carnes dos pobres quadrúpedes que eram obrigados a pastar a pouca grama em volta do acampamento." (SENATORE, 2001, p. 70-8). Medidas extremas são tomadas, como o charqueamento da carne de um cavalo morto pelas flechas dos nativos. Narrativa enviada ao jornal $O$ Estado de $S$. Paulo comunica que a Bandeira havia enviado duas mensagens com pedidos de socorro que a Comissão de Honra não permitiu que fossem publicadas, para evitar alarme entre os familiares do grupo. Comunicada a situação, o governo do Estado decidiu contratar os serviços da Viação Aérea São Paulo (VASP), que enviaria um avião de Goiânia em direção ao acampamento do grupo, atirando-lhe uma carga de cerca de uma tonelada de mantimentos para o regresso. A narrativa do caso dramatiza a situação do grupo e traduz sua sobrevivência como um sinal de heroísmo e capacidade de enfrentar os obstáculos impostos pela natureza sertaneja ao homem civilizado:

Tudo já estava disposto neste sentido, e iam iniciar-se os preparativos do vôo, quando a Bandeira, á qual já se haviam communicado as providencias do governo, enviou mensagens, cujos termos desfizeram as sérias apprehensões causadas pelas anteriores. 
Realmente, numa arrancada empolgante e quasi incrivel para quem conheça, ainda que ligeiramente, o sertão, a "Bandeira", mau grado a presença invisível dos Chavantes, vencera os 40 ou mais leguas que a separava do rio das Mortes, enfrentando as chuvas continuas, os terrenos alagadiços, os corregos volumosos, a densa materia, os cerrados aggressivos e todos os demais empecilhos á sua caminhada. Transpuzera aquelle rio, em cuja margem direita encontrara, afinal, quantidade de caça e peixe sufficiente para refazer-se da sua abstinencia forçada. A ida do avião, que representava o recurso extremo da "Bandeira", tornou-se desnecessaria, pelas circumstancias acima explicadas. (BANDEIRA..., 16 nov. 1937).

A disposição célere em oferecer auxílio demonstra que a Bandeira Anhanguera havia adquirido do poder público não apenas recursos financeiros, mas reconhecimento e legitimidade.

A meta seguinte era cruzar a serra do Roncador para alcançar o planalto onde se formava a bacia dos rios Xingu e Tapajós. Segundo a narração de Francisco Brasileiro, essa serra acabou se tornando, na imaginação de muitos dos caravanistas, um espaço utópico onde seus padecimentos encontrariam fim, "imensa planície de campina verdejante de que a vista não alcançava o fim, onde a caça mansa e abundante pastava...". A subida da vanguarda até o topo revela, entretanto, um terreno árido e pedregoso, onde não havia sinal de caça ou possibilidade de extrativismo. O retorno é angustioso, com o temor do ataque dos xavantes, como também o é a imagem do grupo aos olhos do cronista quando retorna ao acampamento: "Naqueles homens magros, sujos, esfarrapados, famintos, havia expressões sonolentas e aéreas. Uns pesadões, de pernas inchadas; outros derreados e esquálidos, tomados de recalcitrante desinteria. Predominam os olhos tristes, de olhar lento, vago, longínquo, inexpressivo." (BRASILEIRO, 1938, p. 197, 200, 201).

Nesse ponto, avaliando a dificuldade de subir a serra do Roncador, mesmo com os melhores cavalos, o início da estação chuvosa, que duraria até março do ano seguinte, e a dificuldade de reabastecimento, Chicão comunica a Hermano a necessidade de retornar a partir daquele ponto. O líder do grupo resiste à ideia, considerando vergonhoso fazê-lo sem que fosse atingida a meta. Após uma reunião do grupo, foi decidido o regresso antes que as águas inundassem as planícies que precisariam atravessar no retorno a "Porto Anhanguera". Nesse cenário, o subchefe da vanguarda elabora seu balanço das realizações do empreendimento:

Estamos com 4 meses de marcha, com oitenta por cento das realizações: é a primeira vez que se entra nesta margem; é a primeira vez que se entra em uma aldeia chavante; fomos os primeiros a identificar êstes índios como xerentes; é a primeira vez que se galga a serra do Roncador. Nossa coleção entomológica 
é valiosíssima; nossa coleção de aves empalhadas é preciosa; nossa coleção de botânica contem raridades. Temos nossos serviços de engenharia e mineralogia. Enfim, já fizemos bastante! Voltar daqui é levar tudo isso para São Paulo, é provar nosso valor, é voltar vitoriosos! Continuar é arriscar perder tudo, é concorrer com um inevitável fracasso, é facilitar um trambolhão! (BRASILEIRO, 1938, p. 202)

Decidido o regresso a São Paulo, no dia 6 de novembro Hermano envia uma mensagem declarando o compromisso coletivo de reiniciar a expedição em maio do ano seguinte, propondo dessa vez um roteiro pela ilha do Bananal, com o objetivo de transpor a serra do Roncador (MELLO, 1980, p. 234). O retorno a partir da serra do Roncador se dá sob chuvas torrenciais, e as barracas e lonas disponíveis são utilizadas para proteger o material científico coletado. Ao menos, com a chegada ao rio das Mortes, os viajantes encontram caça abundante, o que lhes facilita a viagem de volta. O retorno precoce foi atribuído à falta de recursos em relação ao que havia sido originalmente planejado, ou seja, a aquisição da tropa e a contratação dos peões sertanejos para transporte dos volumes.

Em tal ponto, o excesso de peso confirma-se como verdadeiro estorvo à movimentação do grupo, uma vez que desde o início os técnicos mostram-se intransigentes quanto à manutenção do material coletado e dos instrumentos, pois "[c]ada um se apega aos seus inúmeros caixões, à sua volumosa carga, não querendo sacrificá-la em benefício da marcha, julgando cada qual, em sua extremada dedicação aos seus trabalhos, que era a parte principal, imprescindível da penetração, sem refletir, entretanto, que, por mais precioso que fôsse o seu material, de nada adiantaria si não tivéssemos cavalos para carregá-lo." Observa-se, assim, a verdadeira contradição entre os objetivos exploratórios do grupo e seu propósito científico, que dependia dos animais de carga que Francisco Brasileiro definiu como "verdadeiros amontoados de bugigangas". Ao final da expedição, o chefe da Bandeira chega a concordar com o descarte de considerável parcela do material acumulado, o que só não chega a acontecer porque o padre salesiano Hippolyte Chovelon voluntaria-se para carregá-lo em seu batelão (BRASILEIRO, 1938, p. 128-9, 156, 162).

Por determinação do líder da expedição, um grupo de perfil científico liderado por Bandeira de Mello empreende uma viagem fluvial em direção ao Araguaia e à ilha do Bananal, portando grande parte do equipamento e do material colhido, enquanto o grosso da caravana prossegue até o marco zero. O objetivo era aliviar a marcha e incrementar o acervo botânico e etnográfico da Bandeira, além de coletar novas informações técnicas e médicas, fotografar e filmar os "semicivilizados" índios carajás e javaés, 
evidentemente enfraquecendo eventuais críticas quanto ao valor científico da expedição. Na viagem, esse grupo chega a ficar 48 horas sem alimento. (NÉBIAS, 1940, p. 162)

As narrativas dos dias finais da expedição têm como ponto de inflexão a morte de Hermano, ocorrida em 24 de novembro. Conquanto algumas de suas decisões tenham sido objeto de questionamento, sua figura sempre pairou acima das disputas de poder e dos conflitos interpessoais em que se debatiam os membros da expedição. A explicação de sua morte por Bandeira de Mello não deixa de refletir, aliás, esses conflitos, pois ela é atribuída aos desentendimentos entre as lideranças do grupo, que teriam agravado o estado de saúde de Hermano. Além disso, de acordo com sua avaliação, enquanto o médico da expedição encontrava-se junto ao grupo científico na ilha do Bananal, as decisões acerca de seu tratamento acabaram nas mãos de pessoas inexperientes que não souberam deliberar sua retirada para Santa Leopoldina ou solicitar o envio de um avião para seu transporte para um hospital em Goiânia ou Anápolis (MELLO, 1980, p. 236). Senatore é ainda mais incisivo, definindo o chefe como um "exemplo de disciplina e bondoso com todos, mesmo com os que o traíram e obstacularam a sua missão" e como uma "alma leal que foi vítima dos seus próprios companheiros" (SENATORE, 2001, p. 92). Francisco Brasileiro, por sua vez, escreve que "[n]inguém se priva ao fim predestinado", atentando para a condição crônica da doença que o acometia, sem deixar de registrar as altercações quanto ao futuro da expedição que marcaram os últimos contatos entre eles (BRASILEIRO, 1938, p. 219).

\section{A poesia que se deriva da morte}

Considerando que, até aquele momento, todo o empreendimento havia sido marcado pela conclamação dos esforços públicos pela voz da imprensa escrita e falada, o falecimento de Hermano Ribeiro da Silva haveria de reverberar consideravelmente nos meios jornalísticos, expandindo seu já considerável círculo de alcance. Uma das consequências disso é o afloramento de versões inexatas a respeito dos eventos, como aquela que atribui à expedição o objetivo de solucionar o célebre desaparecimento do explorador inglês Percy Fawcett, em 1925, na região do Araguaia, o que, de fato, tem pouca relação com os fatores que motivaram a iniciativa, e que possivelmente denota o interesse de última hora despertado pela morte do sertanista (MORTO..., 1937). Por outro lado, diversos veículos da imprensa exploraram, até a exaustão, a figura do herói patriota que se sacrifica pelo país. Nota publicada na 
coluna "Ecos", do jornal $O$ Globo, demonstra a difusão da mística do mártir bandeirante para além das fronteiras paulistas:

Espírito bandeirante. A existencia ou invocação dessa força não recorda o phenomeno em que tanto se tem a psychologia moderna quando estuda a transformação social dos sentimentos. É dentro desse angulo que hoje se deve exalçar o espirito bandeirante, isento de violencias e das aventuras tragicas de sangue, mas intacto no seu fundo de ambição e de belleza. Dahi a poesia que se deriva da morte do bello escriptor paulista que empunhava a bandeira dos Anhangueras e vem de morrer de sesão perto do Rio das Mortes. Elle não foi procurar esmeraldas, nem destruir vidas ou fazendas. Foi procurar um pouco de elementos para construcção das partes falhas da nossa ethnographia, um pouco de poesia a mais para os quadros sumptuosos das nossas selvas. Elle ia enriquecer as letras sertanejas, de que já era principe, e trazer achegas á sciencia. O espirito bandeirante, desse modo, como que toma um sentido moderno e purificado pela sua força socializadora. É por isto que a morte de Hermano Ribeiro da Silva nos commove, e a toda a opinião publica com o abalo que sempre provocam as injustiças do destino, ou as fatalidades que não sabemos explicar (ECOS, 1937).

As homenagens ao líder da Bandeira foram efusivas, incluindo a atribuição de um hodônimo na capital (rua Hermano Ribeiro da Silva, na Vila Mariana), missas, tributos e a realização de uma caravana de estudantes da Universidade de São Paulo, que visitou Goiânia a convite do governador Pedro Ludovico. Lá foi desenvolvido um programa de festividades, que culminou com a instalação de uma placa em um pedestal erguido em frente ao palácio de governo em Goiânia, com os dizeres: "A Hermano Ribeiro da Silva, pioneiro intimorato de um Brasil cada vês mais vasto e mais forte, o jornal 'Estado de São Paulo' e a mocidade academica de direito trazem a homenagem e a gratidão da terra de Piratininga - janeiro de 1938" (Á MEMÓRIA..., 1938). Nos anos subsequentes e nas efemérides mais marcantes, os jornais paulistas prestariam homenagens ao sertanista, de modo que é possível afirmar que, entre seus contemporâneos, seu nome foi lembrado com admiração e simpatia. Quanto à iniciativa da Bandeira, desde o retorno dos expedicionários a São Paulo afirmou-se o pleno cumprimento da missão (DIVERSOS..., 1937).

No ano seguinte, as realizações da Bandeira Anhanguera chegam ao público, reacendendo a memória ainda recente do empreendimento. Em setembro de 1938, os jornais anunciam uma exposição de material etnográfico colhido pela Bandeira e pelas missões católicas, evento promovido pela Rádio Bandeirante. Nessa ocasião, são colhidos donativos de estabelecimentos comerciais e manufatureiros, realizando-se também a venda de objetos indígenas em benefício das iniciativas de catequização dos nativos. No mesmo 
mês, chega aos cinemas das maiores cidades brasileiras o longa-metragem (de 69 minutos) "Bandeira Anhanguera: a epopea de Hermano Ribeiro da Silva", produzido por Victor Del Picchia, apresentando ao público o acervo das imagens colhidas ao longo da expedição(VIAGEM..., 1938). Tendo permanecido em cartaz em São Paulo até meados de novembro, é divulgado como "o filme que todo brasileiro deve assistir" (SEGUNDA-FEIRA..., 1938). As resenhas saúdam as fortes emoções despertadas pelo realismo das cenas, embora se dediquem, em sua maior parte, a saudar o espírito patriótico da Bandeira, que se espera ser transmitido ao público atraído por suas virtudes cívicas e humanísticas.

No mesmo ano de 1938 é lançado o romance Cummunká, de Menotti del Picchia, que imagina uma expedição de jornalistas que partem de São Paulo para o Mato Grosso em busca de contato com os xavantes, evidente referência a iniciativas como a Bandeira Anhanguera. Assumindo um tom paródico para exprimir uma crítica à civilização do Ocidente, certamente inspirada pela tensão no cenário internacional, o romance não é generoso em sua representação dos jornalistas - que, portadores do discurso da ancestralidade bandeirante, são movidos exclusivamente pelo desejo de alavancar as vendas de seu jornal a partir da manipulação do público consumidor de notícias sensacionalistas, de livros de aventura e do popularíssimo cinema de peripécias na selva. A imagem dos expedicionários fictícios é caricata e colocada a serviço de um juízo ferino acerca da superficialidade enfatuada da elite urbana paulista. Embora o livro não possa ser considerado uma crítica específica a qualquer empreendimento, faz uso do tema para atender a suas próprias motivações, deixando evidente a rápida "dessacralização" da memória da Bandeira Anhanguera (PICCHIA, 1938) ${ }^{13}$. Entretanto, alguns anos depois, sob a égide da conclamação para a conquista característica do discurso territorial do Estado Novo, os feitos de Hermano Ribeiro da Silva foram saudados por Cassiano Ricardo como demonstração autêntica da continuidade histórica do século XX com o expansionismo colonial, no sentido do "desbravamento do sertão, pela posse efetiva das zonas já conquistadas pelo bandeirismo tradicional." (RICARDO, 1942, p. 13-26).

Do ponto de vista da produção científica, o único artigo derivado diretamente das ações da Bandeira foi o citado relatório de Arnaldo Otávio

\footnotetext{
${ }^{15}$ O livro de Menotti del Picchia pode ser compreendido como a conclusão de espécie peculiar de trilogia em que a última obra reverte contra as duas primeiras. A República 3.000, de 1930, e Kalum, o mistério do sertão, de 1936, são manifestações simplórias do espírito etnocêntrico e destrutivo das sociedades modernas em relação aos ditos "povos selvagens".
} 
Nébias publicado na Revista Brasileira de Geografia. Informativo de cunho científico, dedica-se a uma descrição sumária do território percorrido, reunindo dados geológicos, meteorológicos e cartográficos colhidos pela expedição, além de informações genéricas acerca do relevo, vegetação e navegabilidade dos rios. Seu autor preocupa-se também em descrever os métodos utilizados para a produção dos dados, apresentados ao final do artigo por tabelas informativas sobre o clima da região (NÉBIAS, 1940, p. 155-72).

Do ponto de vista etnográfico, como faltavam aos responsáveis qualquer preparo teórico, as observações registradas eram superficiais, o que talvez possa explicar a má reputação acadêmica da Bandeira, e inclusive a carência de estudos sistemáticos em relação a ela e a outras iniciativas similares na pesquisa universitária contemporânea, exceção feita a uma dissertação de mestrado que analisa o diário de Senatore, mas não aprofunda o estudo da expedição (MONTECCHI, 2001). Peças doadas ao Museu Paulista, no total de oito, fazem hoje parte do acervo do Museu de Arqueologia e Etnologia da USP. As contribuições mais efetivas da Bandeira são, possivelmente, as que derivaram da pesquisa ornitológica realizada por Walter Garbi que, consoante Olivério Pinto, teria permitido a identificação e a catalogação de setenta e duas espécies até então desconhecidas (PINTO, 1938, p. 97-106).

Essa prospecção da história da Bandeira Anhanguera pode ser o primeiro passo para a realização de estudos aprofundados acerca do fenômeno, que é expressivo a respeito de mobilizações oriundas da sociedade civil, mas convergentes com o que seriam os rumos da política estatal durante o Estado Novo. É nesse sentido que se retorna ao significado da aventura. Estudando o trabalho de Simmel, Giorgio Agamben observou o sentido paradoxal atribuído a ela como uma experiência parcial capaz de conferir à vida uma unidade superior, e como uma atitude impetuosa de tomar posse do mundo justamente em circunstâncias em que a capacidade de se proteger dele é substancialmente reduzida em comparação com a vivência ordinária (AGAMBEN, 2018, p. 43). As narrativas aqui acompanhadas dão conta, exatamente, de circunstâncias como essas, em que os empenhos individuais submetem-se a uma ambição conquistadora que, sob a perspectiva deste artigo, somente faz sentido no interior de um característico cenário ideológico que compreende a doutrinação e a ação do Estado, mas que não parte dele. Por meio da configuração desse cenário, torna-se possível a compreensão do substrato em que se desenrolaram eventos subsequentes bem mais conhecidos e explorados pela historiografia, como a campanha da Marcha para Oeste, lançada pelo Estado Novo em 1941, e a expedição Roncador-Xingu, dos irmãos Vilas-Boas, encetada a partir de 1943. 


\section{Referências}

A "BANDEIRA ANHANGUÉRA" embrenhou-se nos sertões. O Estado de S. Paulo, 11 ago. 1937, p. 12.

A BANDEIRA Anhanguéra nos sertões de Goyas e Matto Grosso. Correio Paulistano, 4 set. 1938, p. 10.

ADAMI, Antonio. O rádio com sotaque paulista: Pauliceia Radiofônica. São Paulo: Mérito, 2014.

AGAMBEN, Giorgio. A aventura. Cláudio Oliveira. Belo Horizonte: Autêntica, 2018.

Á MEMORIA do bravo sertanista Hermano Ribeiro da Silva. Careta, Rio de Janeiro, fev. 1938, p. 34.

BANDEIRA Anhanguéra. O Estado de S. Paulo, 4 nov. 1937, p. 8.

BANDEIRA Anhanguéra. O Estado de S. Paulo, 16 nov. 1937, p. 6.

BANDEIRA Anhanguéra. O Estado de S. Paulo, 26 nov. 1937, p. 5.

BARROS, Edir Pina de. Os filhos do Sol: história e cosmologia na organização social de um povo karib: os Kurâ-Bakairi. São Paulo: Edusp, 2003.

BRASILEIRO, Francisco. Na Serra do Roncador. (A vanguarda da Bandeira Anhanguera). Companhia Editora Nacional, 1938.

CONNERTON, Paul. Como as sociedades recordam. Tradução Maria Manuela Rocha. Oeiras, Portugal: 1993.

DIVERSOS expedicionarios da "Bandeira Anhanguera" chegaram hontem a esta capital. Folha da Manhã, São Paulo, 5 dez. 1937, p. 1.

ECOS. O Globo, Rio de Janeiro, 27 nov. 1937, p. 2.

FERREIRA, Antonio Celso. A epopeia bandeirante: letrados, instituições, invenção histórica (1870-1940). São Paulo: UNESP, 2002.

GRANDIN, Greg. Fordlândia. Ascensão e queda da cidade esquecida de Henry Ford na selva. Tradução Nivaldo Montingelli Júnior. Rio de Janeiro: Rocco, 2010.

GRANN, David. Z, a cidade perdida. A obsessão mortal do coronel Fawcett em busca do Eldorado Brasileiro. Tradução Claudio Carina. São Paulo: Companhia das Letras, 2009.

LIMA, Nísia Trindade. Um sertão chamado Brasil. Rio de Janeiro: Revan; IUPERJ; UCAM, 1999.

MELLO, Darcy Bandeira de. Entre índios e revoluções. (Pelos sertões de São Paulo, Mato Grosso e Goiás de 1911 a 1941). São Paulo: Soma, 1980.

MONTECCHI, Acir Fonseca. Teatro de Imagens: a Bandeira Anhangüera através das lentes de Antonio Senatore -1937. Dissertação (Mestrado) - Universidade Federal de Mato Grosso, Cuiabá, 2001 (mimeo).

MONTERO, Paula. Selvagens, civilizados, autênticos. A produção das diferenças nas etnografias salesianas (1920-1970). São Paulo: Edusp, 2012.

MORTO em plena selva o chefe da expedição Anhanguera. Correio da Manhã, Rio de Janeiro, 29 nov. 1937, p. 1.

NA SERRA do Roncador. A marcha da Bandeira Anhanguéra entre os chavantes. (Pu- 
blicação feita á vista do archivo da Bandeira). O Estado de S. Paulo, 17 jul. 1938, p. 9. NA SERRA do Roncador. A marcha da Bandeira Anhanguéra entre os chavantes. (Publicação feita á vista do archivo da Bandeira). Conclusão. O Estado de S. Paulo, 22 jul. 1938, p. 9.

NÉBIAS, Arnaldo Otávio. Bandeira Anhanguera - 1937. Revista Brasileira de Geografia, ano II, n. ${ }^{\circ}$ 2, abr. 1940, p. 155-72.

NO RUMO dos sertões inexplorados. $O$ Estado de S. Paulo, 5 maio 1937, p. 9.

NO RUMO dos sertões inexplorados do Brasil. O Estado de S. Paulo, 9 maio 1937, p. 11.

NO RUMO dos sertões inexplorados. O Estado de S. Paulo, 12 maio 1937, p. 11.

NO RUMO dos sertões inexplorados. O Estado de S. Paulo, 13 maio 1937, p. 11.

NO RUMO dos sertões inexplorados. O Estado de S. Paulo, 14 maio 1937, p. 10.

NO RUMO dos sertões inexplorados. O Estado de S. Paulo, 16 jun. 1937, p. 11.

O DIARIO do bandeirante. O Estado de S. Paulo, Supplemento em rotogravura, n. ${ }^{\circ}$ 124, s. p.

PARTIDA da "Bandeira Anhanguéra". O Estado de S. Paulo, 27 jul. 1937, p. 12.

PICCHIA, Menoti del. Cummunká. Rio de Janeiro: José Olympio, 1938.

PINTO, Olivério Mário de Oliveira. A Bandeira Anhanguera e sua contribuição à ornitologia do rio Araguaia. Boletim Biologico, São Paulo, nova série, n. ${ }^{0} 3$ (3/4), 1938, p. 97-106.

SILVA, Hermano Ribeiro da. Os sertões do Brasil. O Estado de S. Paulo, 26 mar. 1937, p. 3.

SIMMEL, Georg. A aventura. In: SOUZA, Jessé; ÖELZE, Berthold (orgs). Simmel e a modernidade. Tradução Sebastião Rios. Brasília: UnB, 1998, p. 171-87.

REVIVENDO a gloriosa tradição das bandeiras. O Estado de S. Paulo, 4 jul. 1937, p. 10.

REVIVENDO as epopéas dos paulistas de outrora. O Estado de S. Paulo, 3 jul. 1937, p. 10.

RICARDO, Cassiano. As bandeiras do século XX. Cultura Política: Revista mensal de estudos brasileiros. Rio de Janeiro, ano II, n. ${ }^{\circ}$ 11, jan. 1942, p. 13-26.

RUMO ao Araguaya. Goyaz sob o influxo do turismo. O Globo, 9 ago. 1937, p. 8.

SÃO PAULO. Projecto de lei 104, de 1937. Diario Official do Estado de São Paulo, 15 jun. 1937, p. 20-22

SEGUNDA-FEIRA, no Cine São Bento. O Estado de S. Paulo, 19 nov. 1938, p. 3.

SENATORE, Antonio. Viagem à serra do Roncador. 1937. São Paulo: Lemos, 2001.

SILVA, Hermano Ribeiro da. Nos sertões do Araguaia. Narrativa da expedição ás glebas barbaras do Brasil central. São Paulo: Cultura brasileira, 1935.

UMA BELLA iniciativa sertanista dos paulistas. Correio Paulistano, 10 jun. 1937, p. 1.

VILLAS BÔAS, Orlando; VILLAS BÔAS, Cláudio. A Marcha para o Oeste: a epopéia

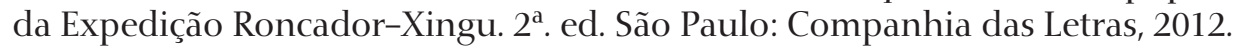

Recebido: 10/7/2019 - Aprovado: 18/2/2020

Editores Responsáveis

Júlio Pimentel Pinto e Flavio de Campos 